\title{
Local variation in endoparasite intensities of bank voles (Clethrionomys glareolus) from ecologically similar sites: morphometric and endocrine correlates
}

\author{
C.J. Barnard ${ }^{1 *}$, J.M. Behnke ${ }^{2}$, A. Bajer ${ }^{3}$, D. Bray ${ }^{4}$, T. Race $^{2}$, \\ K. Frake ${ }^{2}$, J. Osmond ${ }^{2}$, J. Dinmore ${ }^{2}$ and E. Sinski ${ }^{3}$ \\ ${ }^{1}$ Animal Behaviour and Ecology Research Group, ${ }^{2}$ Infection and Immunity \\ Research Group, School of Life and Environmental Sciences, University of \\ Nottingham, University Park, Nottingham, NG7 2RD, UK: ${ }^{3}$ Department of \\ Parasitology, Institute of Zoology, University of Warszawa, ul. \\ Miecznikowa 1, 02-096 Warszawa, Poland: ${ }^{4}$ Animal Behaviour Group, \\ Department of Veterinary Clinical Science and Animal Husbandry, \\ University of Liverpool, Leahurst, Neston, CH64 7TE, UK
}

\begin{abstract}
Much interest has centred recently on the role of adaptive trade-offs between the immune system and other components of life history in determining resistance and parasite intensities among hosts. Steroid hormones, particularly glucocorticoids and sex steroids, provide a plausible mechanism for mediating such trade-offs. A basic assumption behind the hypothesis, however, is that steroid activity will generally correlate with reduced resistance and thus greater parasite intensities. Here, we present some findings from a field study of bank voles (Clethrionomys glareolus) in which we have looked at associations between parasite intensities, anatomical and morphometric measures relating to endocrine function and life history variation in three local populations inhabiting similar but mutually isolated woodland habitats. In general, sites with greater parasite intensities were those in which male C. glareolus had significantly larger adrenal glands, testes and seminal vesicles for their age and body size. Females also showed a site difference in adrenal gland weight. Some aspects of site-related parasite intensity were associated with asymmetry in adrenal gland weight and hind foot length, which may have reflected developmental effects on glucocorticoid activity.
\end{abstract}

\section{Introduction}

Parasite intensities are known to vary considerably between the individuals in host populations. The basis of this variation is multifactorial, but the consequence is aggregation of parasites in particular hosts and a nonrandom distribution across the whole population (Crofton, 1971; Shaw \& Dobson, 1995). The processes

*Fax: +44 (0) 1159513251

E-mail: christopher.barnard@nottingham.ac.uk underlying these phenomena are of central interest in the study of host-parasite community ecology and aggregated distributions are almost an axiom of the field (Gregory \& Woolhouse, 1993; Haukisalmi \& Henttonen, 1999). Much is now understood about the ecological, immunological and demographic factors contributing to different patterns of prevalence and to aggregated abundance of parasitic infections (Anderson \& May, 1978, 1991; Anderson \& Gordon, 1982; Quinnell \& Keymer, 1990; Wakelin \& Blackwell, 1993). Recently, however, interest has focused on the possible role of 
physiological mechanisms underpinning differences in individual life history strategy (Folstad \& Karter, 1992; Sheldon \& Verhulst, 1996; Nunn et al., 2000; Barnard \& Behnke, 2001). In particular, it has been suggested that steroid hormones associated with stress and reproduction may mediate relationships between behaviour and physiology on the one hand and immune function on the other (Grossman, 1985; Folstad \& Karter, 1992; Maier et al., 1994; Hillgarth \& Wingfield, 1997; Maier \& Watkins, 1999; Barnard \& Behnke, 2001), thus leading to trade-offs between different components of life history (Sheldon \& Verhulst, 1996; Barnard \& Behnke, 2001).

There is accumulating evidence for such hormonemediated trade-offs (Wedekind \& Folstad, 1994; Beckage, 1997; Ros et al., 1997; Barnard \& Behnke, 2001), with immunocompetence being conserved or traded off in the face of incentives for investment elsewhere, for instance in territorial aggression or sexual behaviour (Folstad \& Karter, 1992; Barnard et al., 1997a,b; Hillgarth \& Wingfield, 1997). Two factors that are likely to influence such trade-offs are the selection pressure from parasites and the reproductive value of safeguarding future survival. In a series of papers, Barnard et al. (e.g. 1993, 1994, 1996a,b, 1998), have provided evidence for the latter in the context of social rank in male laboratory mice (Mus musculus). So far, however, little attention has been paid to the former. In this paper, we present some findings from a field study of bank voles (Clethrionomys glareolus) in which we have looked at associations between parasite intensities, anatomical and morphometric measures relating to endocrine function and life history variation in three local populations inhabiting ecologically similar but mutually isolated woodland habitats. Analyses of these populations to date (Behnke et al., 2001) have shown significant differences between the woodland sites in the component community structure of helminth parasites, with species dominance, diversity and prevalence differing significantly between sites. Here we focus on abundance of infection and test some predictions about between and within site differences in infection levels based on these analyses and previous work on steroid hormone effects on immunity.

\section{Materials and methods}

Our three study sites were located in the Mazury region of north eastern Poland, an area in which populations of C. glareolus and its parasite community have long been studied (Borkowska, 1999; Pawelczyk \& Sinski, 2000; Bajer et al., 2001). Exact locations of the sites are given in Behnke et al. (2001). The three sites were selected on the basis of their similarity in habitat structure (analysis in Behnke et al., 2001) and their spatial separation (11$15 \mathrm{~km}$ ) from each other, well beyond distances known to have resulted in local genetic differentiation of C. glareolus populations (Gerlach \& Musolf, 2000). Each site comprised mature mixed woodland of Scots pine (Pinus sylvestris) and silver birch (Betula verrucosa), with patches of Norway spruce (Picea abies), alder (Alnus glutinosa) and occasional oaks (Quercus robur). The trees formed a high canopy over most of the area in each case. The shrub layer comprised mainly hazel (Corylus avellana), and ground cover mainly Oxalis acetosella, Convallaria majalis and
Stellaria holostea with patches of moss. The area of the sites ranged from 900 to 1200 ha and each was bounded on one side by a lake shore and on the others by open agricultural land.

Trapping at all three sites took place over a two-week period in September 1999. At each site voles were caught in a mixture of Longworth, Sherman or locally made wooden rodent traps, set out as 100 traps at $20 \mathrm{~m}$ intervals in parallel lines $10 \mathrm{~m}$ either side of tracks through each site. Two traps were place within $2-3 \mathrm{~m}$ of each other at each trapping point. Traps were set over four nights at each site and inspected at dawn and dusk each day. Any traps containing animals were replaced with fresh traps and the animals brought back to the University of Warsaw's field station at Urwitalt (sites 1 and 2) or Pilchy (site 3).

All voles were culled and weighed, and blood smears prepared from blood taken from the heart. They were then sexed and the following morphometric measurements taken: the maximum length of the skull from the nose to the back of the cranium, the width of the skull at the zygomatic arches, the length of the body from nose to anus, the length of the tail, the length of each hind foot and anogenital distance (the latter suggested to correlate with androgenization early in development (Drickamer et al., 1995; Palanza et al., 1995)). Animals were then autopsied. The entire alimentary canal was removed and placed in vials containing 10\% formaldehyde, and liver, lungs and body cavity carefully inspected for helminths. The spleen, kidneys, adrenal glands and, in males, testes and seminal vesicles were removed and weighed. The weight of the seminal vesicles has been shown to be associated with circulating testosterone levels in several species of rodent (Fukazawa \& Iguchi, 1999; Desai \& Kondaiah, 2000; Jarred et al., 2000), including C. glareolus (Tahka et al., 1997) and gonadal hormones generally have been implicated in sex differences in disease resistance (e.g. Klein, 2000). Right and left paired glands were weighed separately. The lenses were also removed from the eyes and dried and later used to calculate the age of each individual (Morris, 1972; Kozakiewicz, 1976).

\section{Recovery of parasites}

\section{Haemoparasites}

Thin blood smears were prepared from drops of blood taken from the heart at autopsy. Blood smears were airdried and fixed in absolute methanol. They were processed further in the UK where each was stained for 45 min in Giemsa's stain (diluted 1:3) in buffer at pH 7.2 and examined under oil immersion (using an Olympus microscope). Initially, sufficient fields of vision were examined to enable up to 200 leukocytes to be inspected for presence of Hepatozoon erhardovae (approximately 200 fields of vision under $\times 100$ objective lens). Each field of vision was also examined for the presence of other species, although these were not quantified at this stage. If the blood smear revealed the presence of other species, during this initial phase of examination, an additional 100 fields of vision (selected for approximately confluent monolayers of cells) were inspected and the number of parasites (Trypanosoma evotomys ) or erythrocytes containing parasites (Bartonella grahamii, Babesia microti and 
Haemobartonella sp.) were recorded and expressed as number of parasites per 100 fields.

\section{Intestinal protozoa}

Individual fresh faecal samples were collected from traps and occasionally from the rectum of animals at autopsy. A few pellets were used to prepare two thin faecal smears from each vole. Smears were then air-dried and fixed in absolute methanol (3-5 $\mathrm{min})$. Later, the first slide from each vole was stained according to modified Ziehl-Neelsen technique (Henriksen \& Pohlenz, 1981). Then, at least 200 fields of vision under $400 \times$ magnification were carefully examined on each slide for presence or absence of Cryptosporidium spp. oocysts. These were identified and distinguished on the basis of their size and morphology. The second faecal smear from each animal was stained for $45 \mathrm{~min}$ using Giemsa solution (1:3) and then examined under $400 \times$ magnification for presence of Giardia spp. cysts. The concentration of cysts and oocysts was expressed as number per 200 fields of vision.

\section{Helminths}

At autopsy in the field stations in Poland, the livers, lungs and body cavity were inspected for helminths and, when present, these were removed, counted and preserved in vials containing $70 \%$ ethanol. The preserved intestines were carefully dissected and examined in Nottingham. All parasites were removed, identified and preserved in $70 \%$ ethanol.

\section{Statistical analysis}

Parametric statistics were used throughout. Data that did not conform to a normal distribution were transformed as $\log _{10} x, \log _{10} x+1$ or square root $x$ as necessary.

\section{Results \\ Differences between sites}

Parasite species recovered from voles at the three sites are shown in table 1 , and summary statistics for abundances of infection by major parasite group in table 2. There was no significant difference in sex ratio between the three sites and the same age class (young adult; age class 2 in Behnke et al., 2001) predominated in all three. However, there were significant differences in the relative proportion of the youngest age class (1) across sites (Behnke et al., 2001), so age was controlled for in all subsequent comparisons. To check for any differences in overall body size, we carried out principal components analysis on the morphometric measures (skull length and width, nose-anus length, length of hind feet) separately for each sex (see also Borkowska, 1999). The first derived component in each case explained $54 \%$ and $55 \%$ of the variance in linear measures in males and females respectively and was strongly positively correlated $(P<0.0001$ in all cases) with each of the measures used. We therefore used this as a composite measure of overall body size. Multifactor analysis of variance, controlling for age, showed a significant difference in overall body size
Table 1. Prevalence values (\%) of higher taxa and individual species of parasites, where identification was possible.

\begin{tabular}{lc}
\hline & \\
Parasites & $\begin{array}{c}\text { Prevalence } \\
(\%)\end{array}$ \\
\hline Haemoparasites $^{1}$ & 89.4 \\
Bacteria & \\
Bartonella grahamii & 41.5 \\
Haemobartonella sp. & 48.0 \\
Protozoa & \\
Hepatozoon erhardovae & 64.2 \\
Trypanosoma evotomys & 20.3 \\
Babesia microti & 0.8 \\
Intestinal protozoa & 69.1 \\
Giardia spp. & 59.1 \\
Cryptosporidium muris $^{2}$ & 1.6 \\
Cryptosporidium parvum & 59.1 \\
Helminths & 85.6 \\
Nematodes & 85.6 \\
Heligmosomum mixtum & 40.3 \\
Heligmosomoides glareoli & 36.0 \\
Syphacia petrusewiczi & 13.7 \\
Aspiculuris tetraptera & 28.8 \\
Mastophorus muris & 10.1 \\
Trichuris muris & 0.7 \\
Cestodes & $\mathbf{1 2 . 9}$ \\
Catenotaenia henttoneni & 7.9 \\
Paranoplocephala gracilis & 0.7 \\
Mesocestoides lineatus & 2.2 \\
Taenia martis & 0.7 \\
Taenia mustelae & 2.2 \\
\hline Prevalence based on & \\
\hline
\end{tabular}

${ }^{1}$ Prevalence based on presence in 100 fields examined under oil immersion ( $\times 100$ objective)

${ }^{2}$ Prevalence based on presence in 200 fields examined under oil immersion ( $\times 100$ objective).

${ }^{3}$ Prevalence based on recovery of worms, following initial autopsy in Poland, recovery of larval stages from the peritoneal cavity at autopsy, preservation of the whole of the intestine and subsequent dissection in the UK.

The figures for higher taxa also include specimens not identified to species level and larval stages. Sample size for helminths was 139, for haemoparasites 123, for Cryptosporidium spp. 124 and for Giardia spp. 137.

between sites in males $\left(F_{2,67}=9.88, P<0.001\right)$, with males at sites 1 and 2 being larger than those at site 3 , but no difference in females.

We then tested for differences in organ weights, focusing on those organs associated with steroid hormone activity. Our earlier analysis (Behnke et al., 2001) showed that sites 1 and 2 were characterized by heavy and widely distributed infections of gut nematodes, particularly Syphacia petrusewiczi and Heligmosomoides mixtum, compared with site 3, though site differences in abundance showed a complex interaction with age and sex. Further analysis here, controlling for age, sex and body size, showed that sites 1 and 2 also yielded the highest abundances of gut protozoan infections $\left(F_{2,14}=6.75, P<0.01\right.$, fig. 1$)$, with no effect of age or sex and no interaction. There were no significant site differences in the abundance of haemoparasite infection. Component community patterns within gut protozoa and haemoparasite groups are the subject of separate analyses (Behnke et al., unpublished). 
Table 2. Mean \pm SE and range of parasite intensities and organ weights for male and female voles.

\begin{tabular}{llc}
\hline & \multicolumn{1}{c}{ Males } & \multicolumn{1}{c}{ Females } \\
\hline Total helminths & $84.2 \pm 57.7(0-4029)(71)$ & $66.9 \pm 42.1(0-2820)(68)$ \\
Total intestinal protozoa & $3.2 \pm 0.6(0-26)(65)$ & $3.9 \pm 0.6(0-21)(58)$ \\
Total haemoparasites & $60.7 \pm 15.6(0-691)(62)$ & $121.6 \pm 42.6(0-1937)(61)$ \\
Weight adrenal glands (mg) & $3.9 \pm 0.2(1.0-9.9)(71)$ & $6.9 \pm 0.5(2-17.8)(68)$ \\
Weight testes (mg) & $65.1 \pm 14.0(6.5-509.4)(71)$ & - \\
Weight seminal vesicles (mg) & $12.1 \pm 2.9(0.0-96.0)(51)$ & - \\
\hline
\end{tabular}

Range and sample size in parentheses. Helminth intensity is expressed as the number of individual parasites, gut protozoa intensity as the number of cysts or oocysts per 200 fields of vision and haemoparasite intensity as the number of individuals or infected cells per 100 fields of vision (see Materials and methods).

On the basis of the helminth and gut protozoan abundances, we thus expected animals at sites 1 and 2 to show evidence of greater adrenocortical and gonadal activity.

Accordingly, analysis of variance, controlling for body size and age, showed significant site differences in the weight of the adrenal glands $\left(F_{2,130}=7.44, P<0.001\right)$, with voles at site 1 having the largest adrenals for their body size (fig. 2). Not surprisingly, there was a significant difference between the sexes $\left(F_{1,130}=47.03, P<0.0001\right)$, but there was also a significant site $\times$ sex interaction $\left(F_{2,130}=3.10, P<0.05\right)$, due to differences in adrenal size between the sexes at site 2 . In males, site 2 was intermediate between sites 1 and 3 , in females site 2 had the lowest mean value. Figure 2 thus shows the mean values analysed separately for each sex. Effects of glucocorticoids on the immune system are often associated with increased levels of androgens (Folstad \& Karter, 1992; Barnard et al., 1996a,b; Poiani et al., 2000).

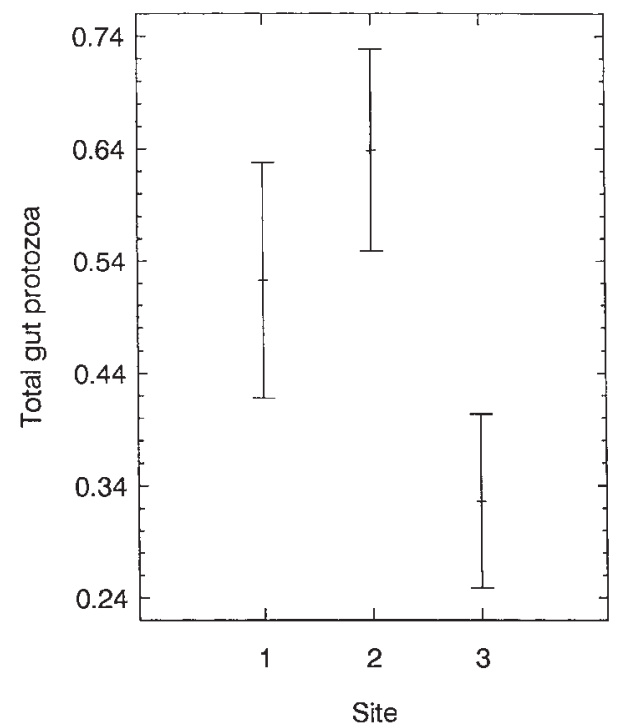

Fig. 1. The mean abundance $\left(\log _{10} x+1\right.$ number of infections per 100 fields of view) of gut protozoa in voles at each site, from twoway analysis of variance of the effects of site and sex (see text). Bars represent least squares deviations.
There is also considerable evidence that sex steroids generally, but particularly androgens, influence resistance to parasites and other pathogens, often reducing it (Grossman, 1985; Folstad \& Karter, 1992; Hillgarth \& Wingfield, 1997; Barnard \& Behnke, 2001). If this was the case in our populations, we should expect similar between-site differences in gonadal measures among males as occurred with adrenal weight. When differences in age and body size were controlled for, fig. 3 a shows this was the case for testes weight $\left(F_{2,66}=9.68, P<0.001\right)$, with the weight of the seminal vesicles being higher in sites 1 and 2 compared with $3\left(F_{2,46}=4.25, P<0.05\right.$, fig. $3 b)$. Anogenital distance, however, showed no significant difference between sites in either sex.

Covariation in adrenal and gonadal measures in males across sites is consistent with differences in seasonal and/or individual patterns of investment in reproduction and stress or immune (gut inflammatory) responses. If differences in glucocorticoid activity reflect stress, however, they may be associated with other measures of stress at the local population level. Morphological fluctuating asymmetry, random departures in bilateral symmetry that are usually presumed to reflect developmental instability (van Valen, 1962; Palmer \& Strobeck, 1986; Møller \& Swaddle, 1997), provides one such measure. In this study, the difference in the length of the left and right hind feet met the criteria for fluctuating asymmetry; signed right-left differences were normally distributed (Kolmogorov-Smirnov one-sample test) with a mean value that did not differ significantly from zero ( $t$-test for a known standard). Analysis of variance of the unsigned asymmetry in hind foot length, controlling for mean foot length as well as body size and age, revealed a significant difference between sites in males $\left(F_{2,65}=3.45\right.$, $P<0.05$ ), with animals from site 1 showing the greatest degree of asymmetry (fig. 4), but no difference in females $\left(F_{2,61}=0.33, \mathrm{NS}\right)$.

\section{Anatomical and morphometric predictors of parasite intensity}

While differences in relative organ weights and fluctuating asymmetry accord with expectation in terms of parasite community structure at the three sites, this does not necessarily indicate a causal association between these measures and parasite intensities. To see whether organ weights and morphological measures predicted 

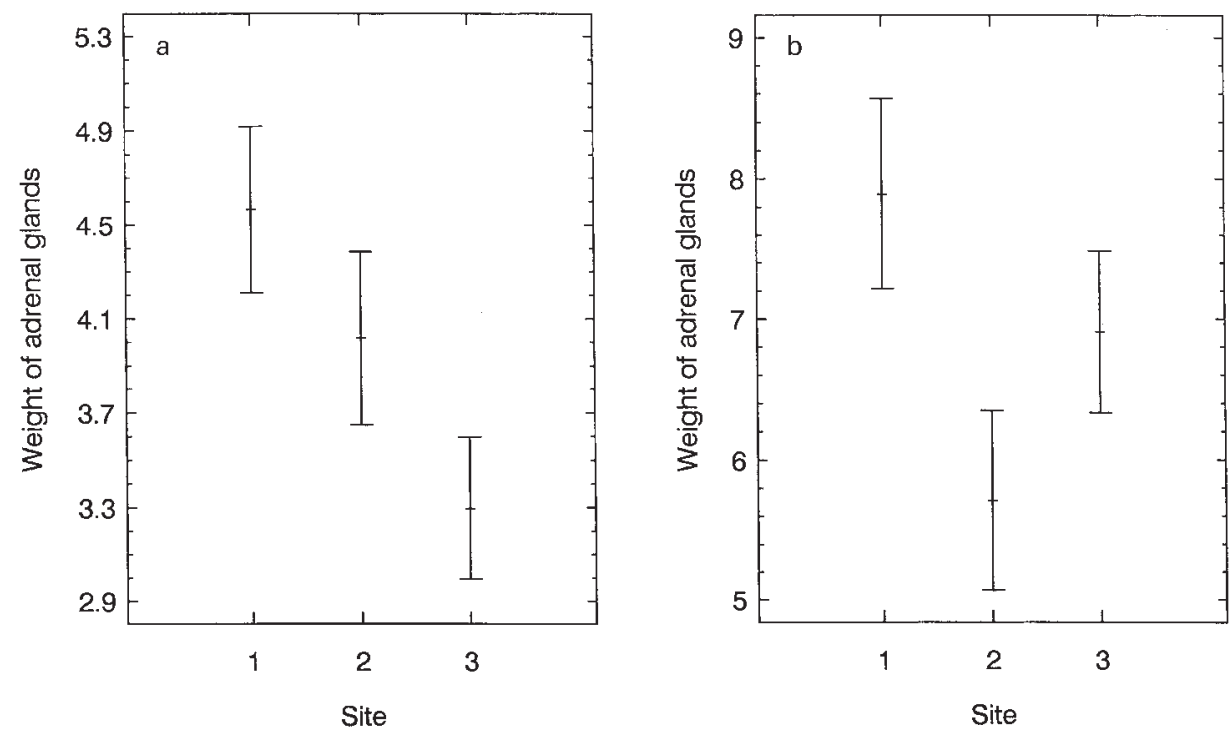

Fig. 2. The mean weight (mg) from one-way analysis of variance of (paired) adrenal glands in (a) males and (b) females at each site. Bars represent least squares deviations.

parasite intensities, therefore, we carried out multiple regression analyses with site as a dummy variable to control for the potentially confounding effects of other differences between sites. Our prediction is that animals showing greater fluctuating asymmetry and/or with larger adrenal glands, testes and seminal vesicles relative to body size will show greater intensities. We also included right-left asymmetry in adrenal gland weight as an independent variable because studies have suggested an association between directional (left-biased) asymmetry in adrenal gland size and dysfunction of the hypothalamic-pituitary-adrenal hormone axis (Szigethy et al., 1994; Abramov et al., 1996; Gerendai \& Halasz,
1997), with greater asymmetry being associated with reduced production of glucocorticoids (Abramov et al., 1996; M. Moshkin, personal communication). Adrenal gland weight in this study also showed significant left bias (paired $t=2.03, P<0.05$ ). However, adrenal weight asymmetry did not show any significant difference across sites $\left(F_{2,114}=0.28\right.$, NS). Nevertheless, if adrenal asymmetry generally leads to a downregulation of glucocorticoids, we should expect a negative relationship between gland asymmetry and parasite intensity, with more asymmetric individuals having lower intensities. As dependent variables in each case we used the total number of each taxonomic group of endoparasites
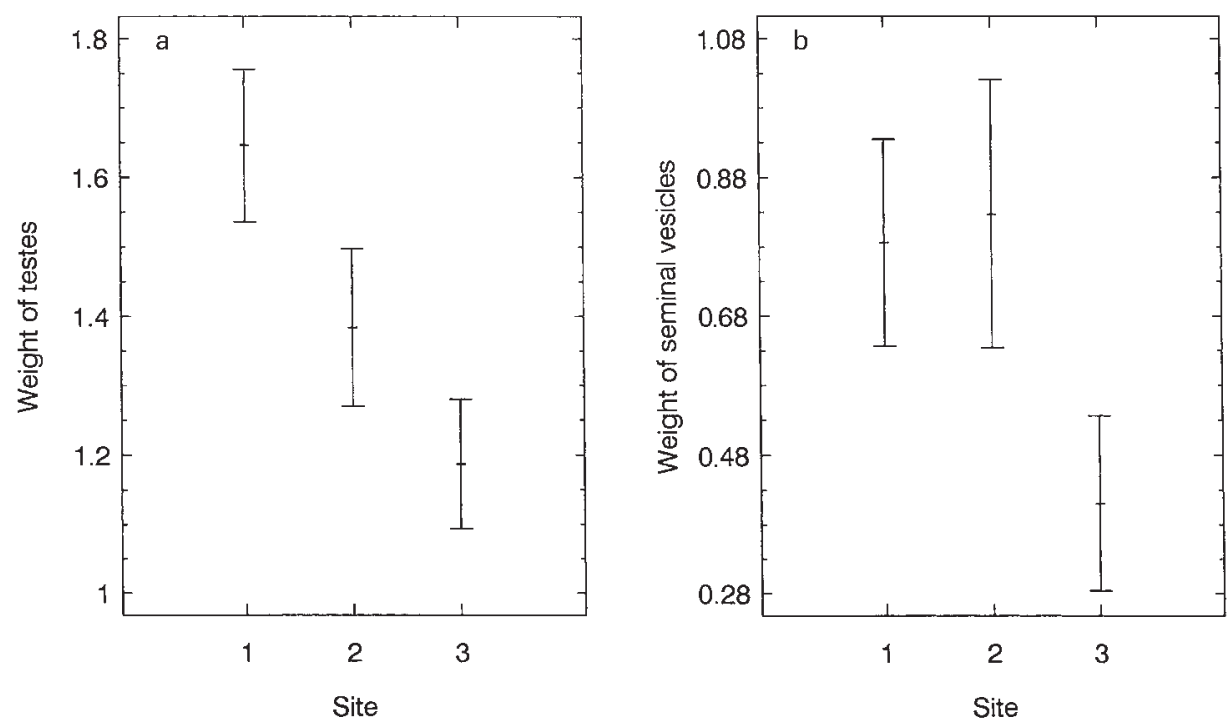

Fig. 3. The mean weight (mg) from one-way analysis of variance of (paired) (a) testes and (b) seminal vesicles in males at each site. Bars represent least squares deviations. 


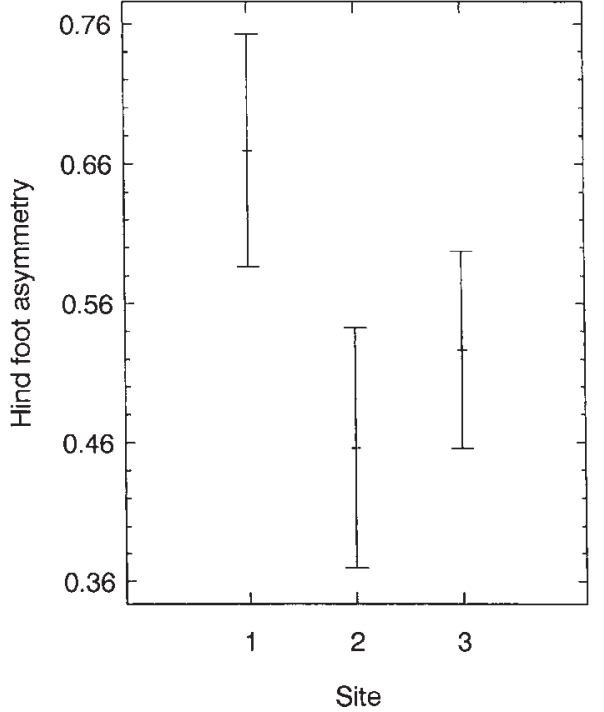

Fig. 4. The mean unsigned hind foot asymmetry $(\mathrm{mm})$ from oneway analysis of variance in males at each site. Bars represent least squares deviations.

recorded (helminths, haemoparasites and gut protozoa) transformed as necessary. Since we are predicting trends in specific directions (positive for the foot asymmetry and weights of adrenal glands, testes and seminal vesicles, negative for adrenal asymmetry), $t$ values are quoted with one-tailed probabilities. Final models included only significant independent variables.

The results revealed a significant independent positive association between total helminth intensity and both adrenal gland $\left(t_{49}=2.09\right.$, one-tailed $P<0.01$, fig. $\left.5 \mathrm{a}\right)$ and seminal vesicle $\left(t_{49}=2.55\right.$, one-tailed $P<0.01$, fig. $\left.5 b\right)$ weights in males, but no significant effects of adrenal gland weight or asymmetry, or morphological measures, emerged for females. Analysis of gut protozoa showed a significant positive association with weight of seminal vesicles $\left(t_{42}=2.20\right.$, one-tailed $P<0.02$, fig. 6a) and a significant negative association with adrenal gland asymmetry in males $\left(t_{42}=-2.00\right.$, one-tailed $P<0.05$, fig. 6b). Haemoparasite intensity showed only a negative relationship with adrenal gland asymmetry $\left(t_{35}=-1.85\right.$, one-tailed $P<0.05$ ). Again, no significant relationships emerged for either group of protozoa among females. Analysis of endoparasite intensities thus bore out several relationships with organ weights predicted on the basis of overall site differences.

Although on necessarily very reduced sample sizes, we also checked for relationships within sites, but only for those independent variables that showed significant relationships across sites. The positive relationships between total helminth intensity and seminal vesicle and adrenal weights remained among males at site 1 (seminal vesicles: $t_{13}=-1.85$, one-tailed $P<0.05$; adrenal glands: $t_{13}=2.49$, one-tailed $P<0.01$ ), but no significant relationships emerged for sites 2 or 3 . Similarly for gut protozoa, the negative relationship with adrenal gland asymmetry (but not the positive relationship with seminal vesicle weight) remained at site $1\left(t_{6}=-2.78\right.$, one-tailed $P<0.001$ ) but not at sites 2 and 3 . However, the relationship between adrenal gland asymmetry and haemoparasites did not hold for any site individually.

While fluctuating asymmetry in hind foot length was not associated directly with any of the measures of parasite intensity, regression analysis within sites, controlling for body size and mean foot length, showed a significant positive relationship between foot asymmetry and adrenal gland weight in males at site $1\left(t_{18}=2.22, P<0.05\right)$, but not at the other two sites.
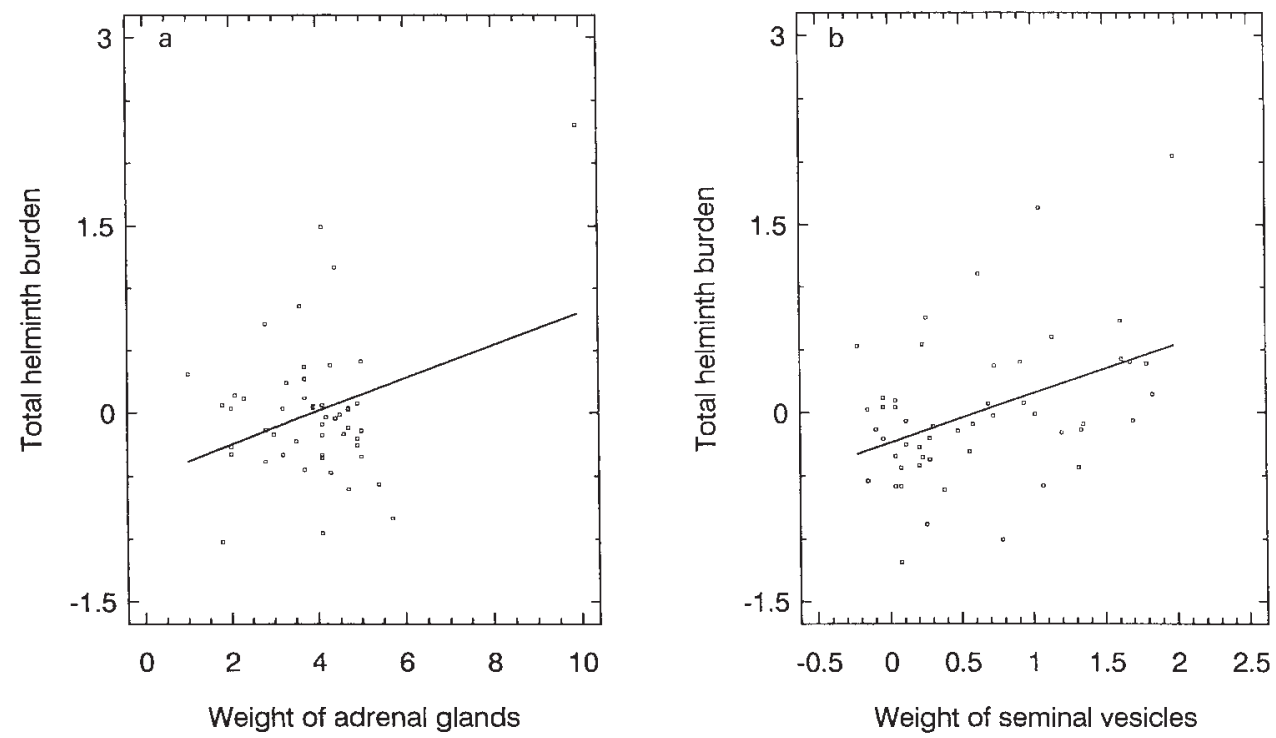

Fig. 5. Component effect (departure from mean value of dependent variable) from multiple regression analysis for the relationship between abundance $\left(\log _{10} x+1\right.$ number of individuals) of helminth infection and weight (mg) of (a) adrenal glands and (b) (log 10 ) seminal vesicles in males. See text. 

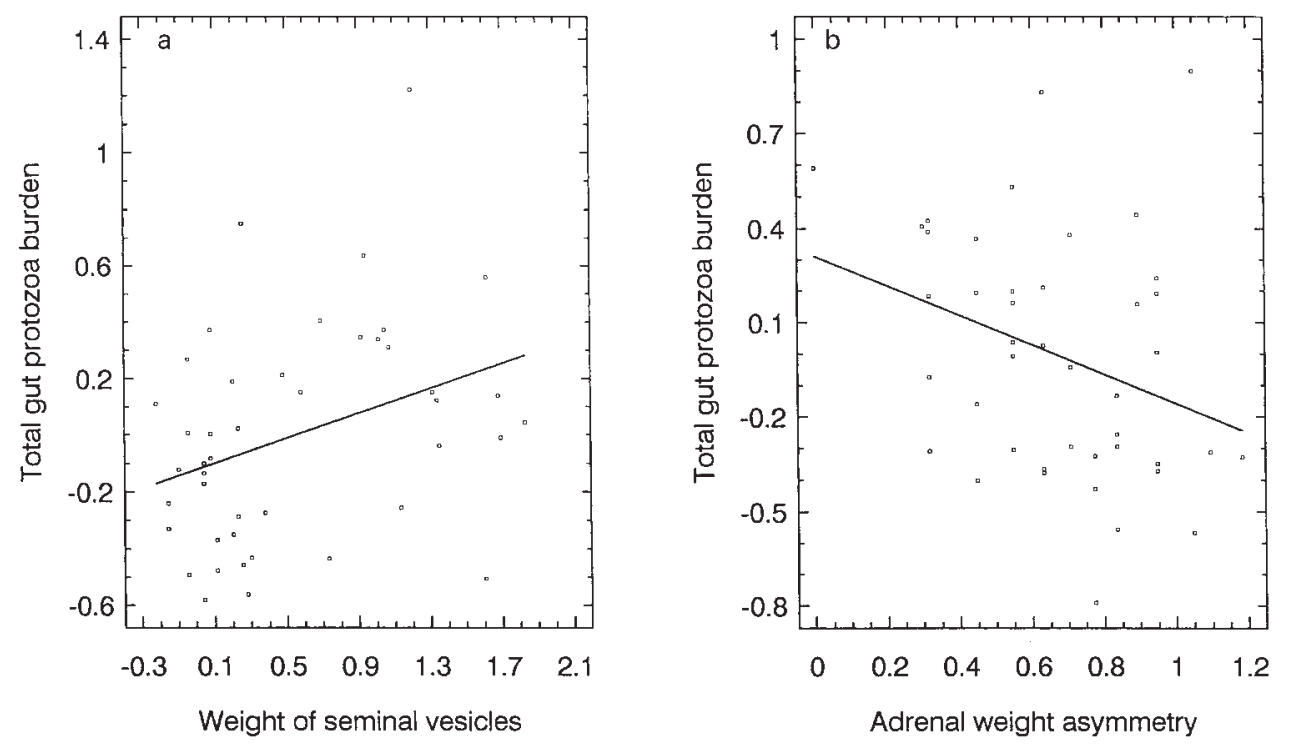

Fig. 6. Component effect from multiple regression analysis for the relationship between abundance $\left(\log _{10} x+1\right.$ number of individuals) of gut protozoan infection and weight $(\mathrm{mg})$ of $(\mathrm{a})\left(\log _{10}\right)$ seminal vesicles and (b) (square root) adrenal weight asymmetry. See text.

\section{Discussion}

The results largely bear out our predictions about site differences in endocrine activity, as judged by the relative weights of adrenal and gonadal glands, and their relationships with parasite intensities. While males and females here showed no overall differences in parasite intensity (see also Escutenaire et al., 2000; Bajer et al., 2001), relationships between organ weights and parasite intensities were confined to males. This is in keeping with other studies showing reduced immunocompetence in male, but not female, C. glareolus during the breeding season (Saino et al., 2000; see also Hazel et al., 2000).

In general, sites with greater or more widespread endoparasite infections were those in which male $C$. glareolus showed significantly larger adrenal glands, testes and seminal vesicles for their age and body size. Females also showed a site difference in adrenal gland weight, concurring with males in having the largest adrenal glands at site 1 . That site differences in parasite intensities and gland weights may have reflected cause and effect relationships between the two was supported by regression analyses across and within sites. In keeping with the established negative effects of glucocorticoid hormones and androgens on resistance to helminths and protozoan infections (e.g. Alexander \& Stimson, 1988; Harder et al., 1994; Barnard et al., 1996a,b; Davies, 1997; Wilckens \& de Rijk, 1997), increased adrenal and seminal vesicle weights in males were associated with higher worm and protozoan intensities. Moreover, reduced directional asymmetry in adrenal gland weight, which reflects increased glucocorticoid secretion in other rodents (Abramov et al., 1996), was associated with greater protozoan intensities in male voles in this study.

That the relationships between endocrine and infection measures shown here are not trivial products of chance differences between sites is suggested by: (i) the maintenance of many of the relationships within particular sites; (ii) the occurrence of others (e.g. with adrenal gland asymmetry) across sites in the absence of between-site differences; and (iii) the existence of independent predictors of endocrine measures which do show site differences but are not themselves directly associated with related parasite intensities. A good example of (iii) is fluctuating asymmetry in hind foot length, which, as a putative measure of developmental instability, was associated with adrenal hypertrophy in males at site 1, where adrenal gland weight was itself a significant predictor of helminth intensity.

The reasons for the reported site differences in parasite intensities and endocrine correlates here are not known. There may have been local geographic effects on the length and/or timing of the breeding season, differences in unmeasured factors such as predation pressure, imposing or relaxing constraints on reproductive investment and influencing stress responses, local differences in genotype and individual quality and so on. Variation in parasite intensity in ecologically similar habitats have been reported in other species and attributed to stochastic immigration and extinction events (Kennedy et al., 1991; Hartvigsen \& Kennedy, 1993) or local differences in hostparasite adaptation (Sire et al., 2001). The important point in the present study, however, is that local population differences were associated with apparent levels of glucocorticoid and androgen activity. The question as to whether this reflects a chronic difference in parasite pressure between sites, and thus selection favouring different patterns of reproductive investment, or whether it reflects a short term response to temporary conditions does not affect the central argument about trade-offs. In the latter case, differences in trade-off would represent different options within local reaction norms (e.g. Stearns \& Koella, 1986), and thus adaptive phenotypic plasticity.

However, while our results are consistent with an 
immunity cost of steroid activity, they do not directly address the question of local variation in hormonemediated immunity trade-offs. The obvious prediction from the current evidence is that immunodepressive hormone activity would turn out to be modulated in relation to current immunocompetence (Barnard \& Behnke, 2001) in those populations showing no hormone-associated variation in parasite intensity. On the basis of the within-site regressions, this would indicate sites 2 and 3 . On the other hand, the hind foot asymmetry data might suggest greater developmental constraint at site 1, and thus, by analogy with Barnard et al.'s (e.g. 1994, 1996a,b) low ranking male mice, a greater likelihood of modulation at that site. However, as Barnard et al. (1996a) have shown, the tendency to modulate among low quality male mice depends on prevailing environmental stressors and disappears under certain conditions. Individual quality is thus a rather weak basis for prediction. Further field work in the coming year will test these predictions.

\section{Acknowledgements}

We are grateful to the University of Nottingham for the provision of travel expenses and to the British Council, UK and the State Committee for Scientific Research (KBN), Poland for financial support for this study (KBN Grants UM 855 and UM 930). We thank Professor M. Kozakiewicz and Dr. R. Halba for use of the field station at Urwitalt (Department of Ecology, Institute of Zoology) and Dr. A. Kowalczewski for use of the field station at Pilchy (Department of Hydrobiology, Institute of Zoology). Finally we wish to acknowledge the support of the forestry departments responsible for the woodland sites utilized in our study (Nadlesnictwa Gizycko, Mikolajki and Orzysz).

\section{References}

Abramov, V.V., Karmatskikh, O.L., Kozlov, V.A. \& Oskina, I.N. (1996) Functional asymmetry of adrenal glands in CBA $\times$ C57BL/6 F-1 mice. Doklady Akademii Nauk 347, 831-833.

Alexander, J. \& Stimson, W.H. (1988) Sex hormones and the course of parasitic infection. Parasitology Today 4, 189-193.

Anderson, R.M. \& Gordon, D.M. (1982) Processes influencing the distribution of parasite numbers within host populations with special emphasis on parasite-induced host mortalities. Parasitology 85, 373-398.

Anderson, R.M. \& May, R.M. (1978) Regulation and stability of host-parasite population interactions. I. Regulatory processes. Journal of Animal Ecology 47, 219-247.

Anderson, R.M. \& May, R.M. (1991) Infectious diseases of humans: dynamics and control. Oxford University Press.

Bajer, A., Pawelczyk, A., Behnke, J.M., Gilbert, F.S. \& Sinski, E. (2001) Factors affecting the component community structure of haemoparasites in bank voles (Clethrionomys glareolus) from the Mazury Lake District region of Poland. Parasitology 122, 43-54.
Barnard, C.J. \& Behnke, J.M. (2001) From psychoneuroimmunology to ecological immunology: life history strategies and immunity trade-offs. pp. 35-47 in Ader, R., Felten, D. \& Cohen, N. (Eds) Psychoneuroimmunology, 3rd edn. San Diego, Academic Press.

Barnard, C.J., Behnke, J.M. \& Sewell, J. (1993) Social behaviour, stress and susceptibility to infection in house mice (Mus musculus): effects of duration of grouping and aggressive behaviour prior to infection on susceptibility to Babesia microti. Parasitology 107, 183-192.

Barnard, C.J., Behnke, J.M. \& Sewell, J. (1994) Social behaviour and susceptibility to infection in house mice (Mus musculus): effects of group size, aggressive behaviour and status-related hormonal responses prior to infection on resistance to Babesia microti. Parasitology 108, 487-496.

Barnard, C.J., Behnke, J.M. \& Sewell, J. (1996a) Social status and resistance to disease in house mice (Mus musculus): status-related modulation of hormonal responses in relation to immunity costs in different social and physical environments. Ethology 102, 63-84.

Barnard, C.J., Behnke, J.M. \& Sewell, J. (1996b) Environmental enrichment, immunocompetence and resistance to Babesia microti in male laboratory mice. Physiology and Behaviour 60, 1223-1231.

Barnard, C.J., Behnke, J.M., Gage, A.R., Brown, H. \& Smithurst, P.R. (1997a) Modulation of behaviour and testosterone concentration in immunodepressed male laboratory mice (Mus musculus). Physiology and Behaviour 61, 907-917.

Barnard, C.J., Behnke, J.M., Gage, A.R., Brown, H. \& Smithurst, P.R. (1997b) Immunity costs and behavioural modulation in male laboratory mice (Mus musculus ) exposed to the odour of females. Physiology and Behaviour 62, 857-866.

Barnard, C.J., Behnke, J.M., Gage, A.R., Brown, H. \& Smithurst, P.R. (1998) Maternal effects on the development of social rank and immunity trade-offs in male laboratory mice (Mus musculus). Proceedings of the Royal Society of London Series B 265, 2087-2093.

Beckage, N.E. (Ed.) (1997) Parasites and pathogens: effects on host hormones and behavior. New York, Chapman and Hall.

Behnke, J.M., Barnard, C.J., Bajer, A., Bray, D., Dinmore, J., Frake, K., Osmond, J., Race, T. \& Sinski, E. (2001) Variation in the helminth community structure in bank voles (Clethrionomys glareolus) from three comparable localities in the Mazury Lake District region of Poland. Parasitology 123, 401-414.

Borkowska, A. (1999) Genetic and morphological variation among populations of the bank vole Clethrionomys glareolus from north-eastern Poland: the seasonal aspect. Zeitschrift für Saugetierkunde 64, 285-297.

Crofton, H.D. (1971) A quantitative approach to parasitism. Parasitology 62, 179-193.

Davies, I.B. (1997) The effects of hormone treatment on social status-related differences in infection with Babesia microti in adult male CFLP mice. Unpublished PhD thesis, University of Nottingham.

Desai, K.V. \& Kondaiah, P. (2000) Androgen ablation results in differential regulation of transforming 
growth factor beta isoforms in rat male accessory sex organs and epididymis. Journal of Molecular Endocrinology 24, 253-260.

Drickamer, L.C., Saal, F.S. vom, Marriner, L.M. \& Mossman, C.A. (1995) Anogenital distance and dominance status in male house mice (Mus domesticus ). Aggressive Behaviour 21, 301-309.

Escutenaire, S., Chalon, P., Verhagen, R., Heyman, P., Thomas, I., Karelle-Bui, L., Avsic-Zupanc, T., Lundkvist, A., Plyusnin, A. \& Pastoret, P.P. (2000) Spatial and temporal dynamics of Puumala hantavirus in red bank vole (Clethrionomys glareolus) populations in Belgium. Virus Research 67, 91-107.

Folstad, I. \& Karter, A.J. (1992) Parasites, bright males and the immunocompetence handicap. American Naturalist 139, 603-622.

Fukazawa, Y. \& Iguchi, T. (1999) Effects of hormones and growth factors on the development of the male mouse reproductive tract in vitro. Zoological Science 16, 153-160.

Gerendai, I. \& Halasz, B. (1997) Neuroendocrine asymmetry. Frontiers in Neuroendocrinology 18, 354-381.

Gerlach, G. \& Musolf, K. (2000) Fragmentation of landscape as a cause for genetic subdivision in bank voles. Conservation Biology 14, 1066-1074.

Gregory, R.D. \& Woolhouse, M.E.J. (1993) Quantification of parasite aggregation: a simulation study. Acta Tropica 54, 131-139.

Grossman, C.J. (1985) Interactions between the gonadal steroids and the immune system. Science 227, 257-261.

Harder, A., Danneschewski, A. \& Wunderlich, F. (1994) Genes of the mouse H-2 complex control the efficacy of testosterone to suppress immunity against the intestinal nematode Heterakis spumosa. Parasitology Research 80, 446-448.

Hartvigsen, R. \& Kennedy, C.R. (1993) Patterns in the composition and richness of helminth communities in brown trout, Salmo trutta, in a group of reservoirs. Journal of Fish Biology 43, 603-615.

Haukisalmi, V. \& Henttonen, H. (1999) Determinants of helminth aggregation in natural host populations: individual differences or spatial heterogeneity? Ecography 22, 629-636.

Hazel, S.M., Bennett, M., Chantrey, J., Bown, K., Cavanagh, R., Jones, T.R., Baxby, D. \& Begon, M. (2000) A longitudinal study of an endemic disease in its wildlife reservoir: cowpox and wild rodents. Epidemiology and Infection 124, 551-562.

Henriksen, S. \& Pohlenz, J. (1981) Staining of cyptosporidia by modified Ziehl-Neelsen technique. Acta Veterinaria Scandinavica 22, 594-596.

Hillgarth, N. \& Wingfield, J.C. (1997) Testosterone and immunosuppression in vertebrates: implications for parasite-mediated sexual selection. pp. 143-155 in Beckage, N.E. (Ed.) Parasites and pathogens; effects on host hormones and behavior. London, Chapman and Hall.

Jarred, R.A., Cancilla, B., Prins, G.S., Thayer, K.A., Cunha, G.R. \& Ridbridger, G.P. (2000) Evidence that estrogens directly alter androgen-regulated prostate development. Endocrinology 141, 3471-3477.

Kennedy, C.R., Hartvigsen, R. \& Halvorsen, O. (1991) The importance of fish stocking in the dissemination of parasites throughout a group of reservoirs. Journal of Fish Biology 38, 541-552.

Klein, S.L. (2000) Hormones and mating system affect sex and species differences in immune function among vertebrates. Behavioural Processes 51, 149-166.

Kozakiewicz, M. (1976) The weight of the eye lens as a proposed age indicator of the bank vole. Acta Theriologia 21, 314-316.

Maier, S.F. \& Watkins, L.R. (1999) Bidirectional communications between the brain and the immune system: implications for behaviour. Animal Behaviour 57, 741-751.

Maier, S.F., Watkins, L.R. \& Fleshner, M. (1994) Psychoneuroimmunology: the interface between behavior, brain and immunology. American Psychologist 49, 1004-1017.

Møller, A.P. \& Swaddle, J. (1997) Asymmetry, developmental stability and evolution. Oxford, Oxford University Press.

Morris, P. (1972) A review of mammalian age determination methods. Mammal Review 2, 69-104.

Nunn, C.L., Gittelman, J.L. \& Antonovics, J. (2000) Promiscuity and the primate immune system. Science 290, 1168-1170.

Palanza, P., Parmigiani, S. \& Saal, F.S. vom (1995) Urine marking and maternal aggression of wild female mice in relation to anogenital distance at birth. Physiology and Behaviour 58, 827-835.

Palmer, A.R. \& Strobeck, C. (1986) Fluctuating asymmetry: measurement, analysis, pattern. Annual Review of Ecology and Systematics 17, 391-421.

Pawelczyk, A. \& Sinski, E. (2000) Prevalence of IgG antibodies response to Borrelia burgdorferi in populations of wild rodents from the Mazury Lake District region of Poland. Annals of Agricultural and Environmental Medicine 7, 79-83.

Poiani, A., Goldsmith, A.R. \& Evans, M.R. (2000) Ectoparasites of house sparrows (Passer domesticus): an experimental test of the immunocompetence handicap hypothesis. Behavioural Ecology and Sociobiology 47, 230-242.

Quinnell, R.J. \& Keymer, A.E. (1990) Acquired immunity and epidemiology. pp. 317-343 in Behnke, J.M. (Ed.) Parasites: immunity and pathology. London, Taylor and Francis.

Ros, A.F.G., Groothuis, T.G.G. \& Apanius, V. (1997) The relation among gonadal steroids, immunocompetence, body mass and behavior in young black headed gulls (Larus ridibundus ). American Naturalist 150, 201-219.

Saino, N., Canova, L., Fasola, M. \& Martinelli, R. (2000) Reproduction and population density affect humoral immunity in bank voles under field experimental conditions. Oecologia 124, 358-366.

Shaw, D.J. \& Dobson, A.P. (1995) Patterns of macroparasite abundance and aggregation in wildlife populations: a quantitative review. Parasitology (Suppl.) 111, S111-S133.

Sheldon, B.C. \& Verhulst, S. (1996) Ecological immunology: costly parasite defences and trade-offs in evolutionary ecology. Trends in Ecology and Evolution 11, 317-321.

Sire, C., Langland, J., Barral, V. \& Théron, A. (2001) Parasite (Schistosoma mansoni) and host (Biomphalaria 
glabrata) genetic diversity: population structure in a fragmented landscape. Parasitology 122, 545-554.

Stearns, S.C. \& Koella, J. (1986) The evolution of phenotypic plasticity in life-history traits: predictions for norms of reaction for age- and size-at-maturity. Evolution 40, 893-913.

Szigethy, E., Conwell, Y., Forbes, N.T., Cox, C. \& Caine, E.D. (1994) Adrenal weight and morphology in victims of completed suicide. Biological Psychology 36, 374-380.

Tahka, K.M., Zhuang, Y.H., Tahka, S. \& Tuohimaa, P. (1997) Photoperiod-induced changes in androgen receptor expression in testes and accessory sex glands of the bank vole, Clethrionomys glareolus. Biology of Reproduction 56, 898-908.
Valen, L. van (1962) A study of fluctuating asymmetry. Evolution 16, 125-142.

Wakelin, D. \& Blackwell, J.M. (1993) Genetic variation in immunity to parasitic infections. pp. 3-22 in Warren, K.S. (Ed.) Immunology and molecular biology of parasitic infections. Boston, Blackwell Scientific Publications.

Wedekind, C. \& Folstad, I. (1994) Adaptive or nonadaptive immunosuppression by sex hormones? American Naturalist 143, 936-938.

Wilckens, T. \& Rijk, R. de (1997) Glucocorticoids and immune function: unknown dimensions and new frontiers. Immunology Today 18, 418-424.

(Accepted 16 October 2001) (C) CAB International, 2002 